\title{
Bevacizumab/Topotecan Regimen
}

National Cancer Institute

\section{Source}

National Cancer Institute. Bevacizumab/Topotecan Regimen. NCI Thesaurus. Code C160536.

A regimen consisting of topotecan and bevacizumab that may be used in the treatment of certain ovarian, peritoneal, and fallopian tube cancers. 